\title{
Nascent Entrepreneurship: Exploratory Research Based on Systematic Literature Review and Text Analysis
}

\author{
KRISZTOFER SZABÓ* \\ *Corvinus University of Budapest, Doctoral School of Business and Management; \\ krisztofer.szabo@uni-corvinus.hu
}

DOI: $10.14267 / 978-963-503-867-1 \_14$

\begin{abstract}
A brilliant idea means nothing if it stays in someone's mind and doesn't come to life. The process of an idea developed into a new business is very unstable, like a balloon in the wind that can blow in any possible direction. Sometimes the idea gets thrown away, sometimes it creates something extraordinary. Studies on nascent entrepreneurs contribute to the understanding of the factors affecting the intention of an individual to become an entrepreneur. Nascent entrepreneurship is a rather new topic of research. There are large number of journals on the topic only since the early 2000's. There are several challenges in defining the topic accurately since the beginning and the end of the process is not always clear. Sometimes it is difficult to distinguish between the idea phase and the ongoing work in progress. In addition, research results are difficult to compare with each other because of conceptual uncertainties and different approaches. In this paper the most important literary background related to nascent entrepreneurship is presented. In this study, keyword searches reveal the most frequently researched conceptual approaches to the intention of starting a new business. In the critical analysis of selected papers, the research is confined to the field of business and management and economics, which I explore with the steps of the Systematic Literature Review methodology. In the comprehensive literature review is based on bibliometric analysis and quantitative text analysis. Results, proposals and future research areas are also presented.
\end{abstract}

Keywords: nascent entrepreneurship, systematic literature review, bibliometric analysis, text analysis

Funding: The author did not receive any grant or institutional support in relation to the study's preparation. 


\section{Introduction}

The importance of studying entrepreneurship should be undisputable, since that, entrepreneurship is the process brought about by individuals of identifying new opportunities and converting them into marketable products or services (Schaper \& Volery, 2004). It has great relevance to investigate and analyse the beginning parts of being an entrepreneurship to get better understanding. Entrepreneurship studies at individual level revealed a number of theoretical and empirical approaches to explaining new companies' births, often from a process approach (Gelderen, et al. 2006; Dimov, 2007; Teece, 2007; Harper, 2008). Furthermore, number of conceptual definitions have been written in the recent years, and the term of nascent entrepreneurship was created. With the method of systematic literature review a better understanding could be established from the last 20 years about the topic. In the field of entrepreneurship literature, a new venture is defined as an enterprise is not older than six to eight years. One recognized researcher on the entrepreneurial creation studies, Biggadike (1979) set the limit at an eight-year time period for new ventures to reach the level of existing companies. Nonetheless, the most studies in the last years, seems to agree on six years of age or less (Brush, 1995; Kunkel, 1991; Robinson, 1999; Jáki et. al 2019; Shrader et al., 2000).

The definition of a nascent entrepreneur is difficult to determine because it is often unclear where the process begins and will be ends. Hopp \& Sonderegger (2015) define it as teams and individuals who (1) want to start a new business, (2) have already done some entrepreneurial activities to help start business, (3) who expect to own at least part of the new business and (4) who do not have any existing business. Therefore, the difference between a nascent entrepreneur and an actual entrepreneur is that the latter is a person who has already started and operates the business (van Stel et al., 2007). However, the term 'nascent entrepreneur' does not exclude entrepreneurs who already have experience from previous enterprises. Accordingly, the 'nascent' reflects the current and ongoing efforts to create a new business (Hopp \& Sonderegger, 2015). Researchers have chosen very diverse research approaches in the nascent entrepreneurship over the last two decades. It is important to review existing studies in order to prepare a new research. Therefore, I aim to prepare an exploratory study with systematic literature review about nascent entrepreneurship to identify the most popular journals and make quantitative research to find the most relevant keywords. This will narrow down the boundaries and find new guidelines for future research. 


\section{Methods}

In order to identify the articles, I focused to 'Scopus' scientific online database. By using this electronic archive, I was able to create a focused and comprehensive literature review. For searching and filtering purposes, the following keyword was used: 'nascent entrepr*' (where * stands for an indefinite number of free characters). I intentionally used one search keyword to focus the most on the topic. To determine the final results, I performed a four steps search. Firstly, in the 'base search' I defined the following restrictions:

- considered to articles and reviews only;

- published between 2000 and 2020;

- searched in titles, keywords and abstracts;

- delamination to only Business, Management and Accounting subject area.

These conditions gave me the possibility to focus on the current state of exploratory research both on time and on the subject. This literature search method resulted in a list of 666 articles. There were too many articles in this search, thus I narrowed down the list by looking only for the title and/or keywords to give a greater chance of finding relevant results. On the next step, the keywords and abstracts searches were eliminated, focusing only on nascent entrepreneurship appearing the titles. All other filter conditions remained unchanged. This search resulted in 147 articles. Thirdly, one restriction has changed, the search filtered only for keywords (leaving the titles and abstracts) which resulted in 189 papers. I identified that, there are matching hits between the results of the last two filtered searches. Consequently, the results were aggregated (final filtered criterion was search in titles OR keywords, all other restrictions as described above). The final list has included 257 different articles. 
Figure 1: The research model of Systematic Literature Review

\begin{tabular}{|c|c|c|c|}
\hline Steps & Search & Restrictions & Hits \\
\hline Base search & $\begin{array}{l}\text { - Scopus } \\
\text { - Keyword: "nascent entrepr*" }\end{array}$ & $\begin{array}{l}\text { - Search in: Title, Keywords, Abstract } \\
\text { - Journal articles and reviews only } \\
\text { - Year: } 2000-2020 \\
\text { Subject area: Business, } \\
\text { Management and Accounting }\end{array}$ & 666 different articles \\
\hline Filtered search I. & $\begin{array}{l}\text { - Scopus } \\
\text { - Keyword: "nascent entrepr*" }\end{array}$ & $\begin{array}{l}\text { - Search in: Only Title } \\
\text { - Journal articles and reviews only } \\
\text { - Year: } 2000-2020 \\
\text { Subject area: Business, } \\
\text { Management and Accounting }\end{array}$ & 147 articles \\
\hline Filtered search II. & $\begin{array}{l}\text { - Scopus } \\
\text { - Keyword: "nascent entrepr*" }\end{array}$ & $\begin{array}{l}\text { - Search in: Only Keywords } \\
\text { - Journal articles and reviews only } \\
\text { - Year: } 2000-2020 \\
\text { Subject area: Business, } \\
\text { Management and Accounting }\end{array}$ & 189 articles \\
\hline Final search & $\begin{array}{ll}\text { - Scopus } \\
\text { - Keyword: "nascent entrepr*" }\end{array}$ & $\begin{array}{l}\text { - Search in: Only Title OR Keywords } \\
\text { - Journal articles and reviews only } \\
\text { - } \quad \text { Subject area: Business, } \\
\text { Management and Accounting }\end{array}$ & 257 differe \\
\hline
\end{tabular}

Source: own illustration

\section{Results}

In the subsequent parts, I conducted bibliometric analysis and quantitative text analysis, which results come to introduce.

\section{Bibliometric analysis}

Analysing the time series of the selected articles (between 2000 and 2020), it seems that the largest number of journal publications in this field were published in the last year (see Figure 2). It is good proof of the topic being increasingly in the focus of scientific attention. 
Figure 2: Trends of published articles between 2000-2020

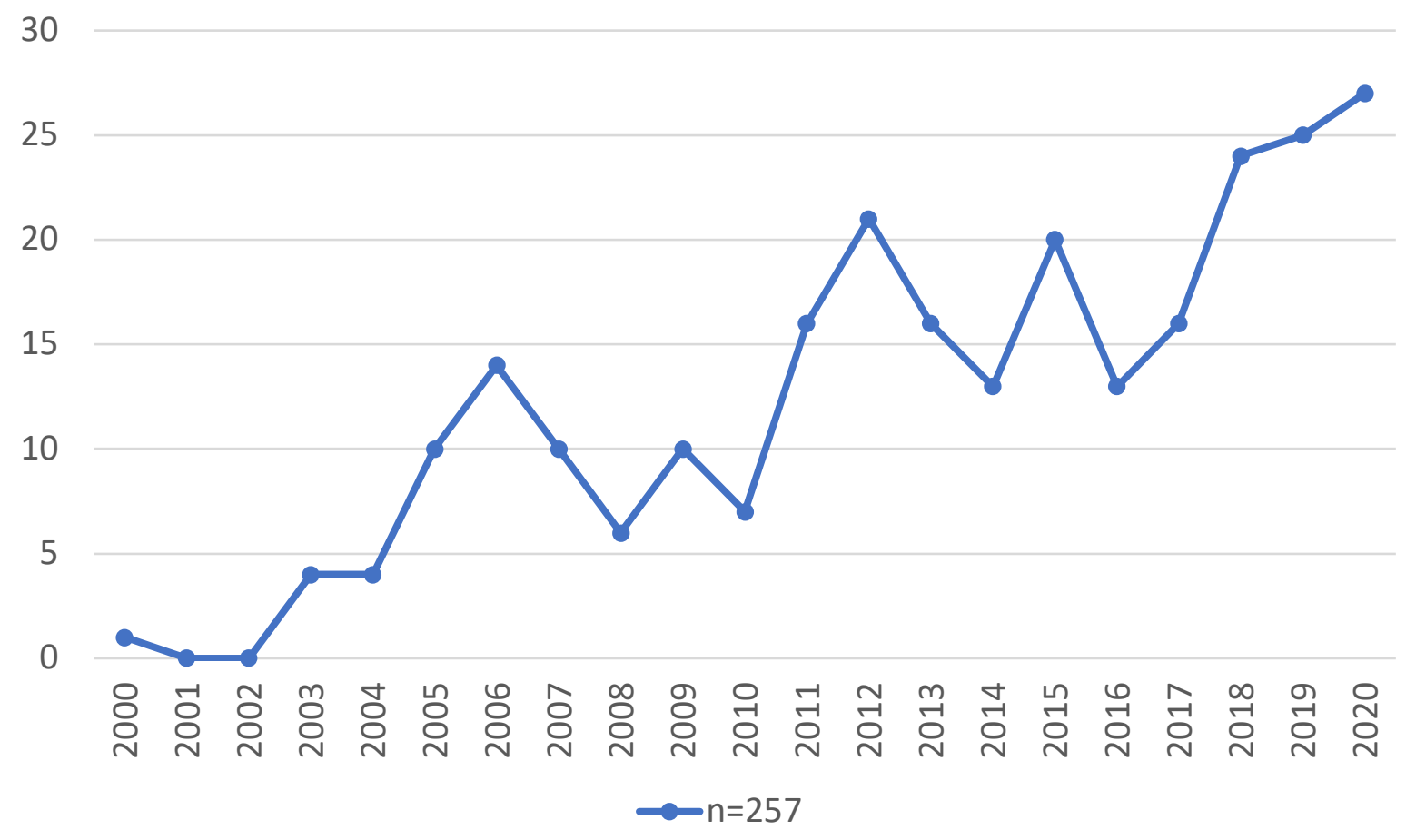

Source: own illustration by Scopus database

Regarding the journals' analysis and rankings analysis, these articles were filtered based on the quality by Scimago Journals Ranking (SJR). Q1, Q2, Q3 and Q4 categories are distinguished where Q1 is the highest quality. In Figure 3, it seems the most articles published in high ranked journals (64\% of the articles have Q1, 23\% papers have Q2 ranked, and no more than $13 \%$ have in lower category journals). These data show that, the elite of academic public are interested in this scientific field especially. Accordingly, high-quality research is made continuously in the topic, which is a great option to read and collect professional literature. I can build my future research through them and publishing in Q1 or Q2 ranked journals probably later. 
Figure 3: Number of articles by Scimago Journal Ranking

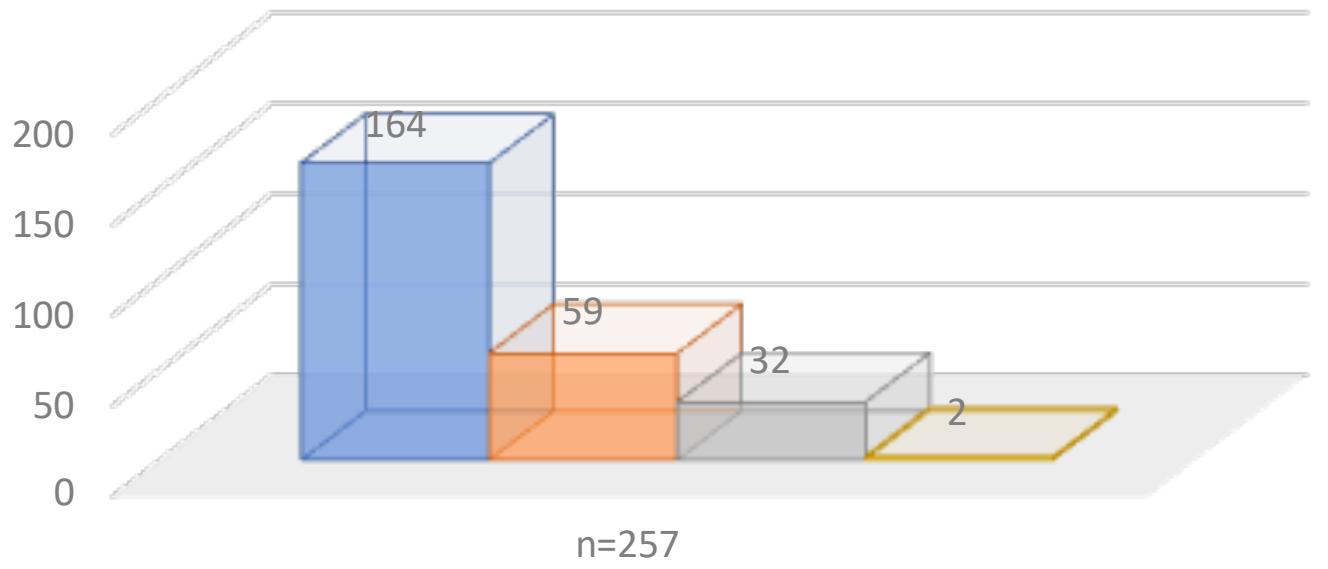

Q1 $\square$ Q2 $\square$ Q3 $\square$ Q4

Source: own illustration by Scopus database

At the end of the bibliometric research, a list of TOP 10 journals was created based on the number of articles (see Table 1). In this list, there are only two lower quality journals that prove the high-quality attention to this research theme once again. Small Business Economics Journal has the largest number of papers in this list, which is a highly ranked journal in the field of business and management sciences. The topic is well defined (not interdisciplinary), and primarily publishing in the entrepreneurial journals. In addition, this list also shows that, which journals are the most relevant for future research. 
Table 1: Summary of the top 10 journals contains the SJR

\begin{tabular}{llll}
\hline Nr. & Source Title & $\begin{array}{l}\text { SJR } \\
\text { ranking }\end{array}$ & Number of hits \\
\hline 1. & Small Business Economics & Q1 & 41 \\
2. & Entrepreneurship and Regional Development & Q1 & 13 \\
3. & Journal of Developmental Entrepreneurship & Q3 & 12 \\
4. & International Journal of Entrepreneurial Behaviour and & Q1 & 11 \\
& Research & Q1 & 11 \\
5. & Journal of Business Venturing & Q1 & 11 \\
6. & Journal of Business Venturing Insights & Q1 & 11 \\
7. & Journal of Small Business Management & Q1 & 10 \\
8. & International Entrepreneurship and Management Journal & 9 \\
9. & International Journal of Entrepreneurship and Small & Q2 & \\
& Business & & 7 \\
10. & Entrepreneurship: Theory and Practice & Q1 & \\
\hline
\end{tabular}

Source: own illustration by Scopus database

\section{Text analysis}

The second part of the quantitative analysis is to examine the selected articles' titles and keywords with text analysis methods. I used the 'WORDij' software for the frequently analysis of used words. These words have illustrated by word cloud below. Figure 4 shows the most frequently 30 words in paper titles, and Figure 5 illustrates the results in paper keywords. (Where the font size is larger, it was more frequently applied as a keyword. The green and orange colours show the matching words between the two analysis.) Beginning of the analysis started, I removed the words that did not contain relevant information (conjunctions definite and indefinite articles and other language elements) by subjective professional filtering content. With this method, only the words with thematic meaning remained in the analysis. 
Figure 4: Most frequently 30 words in paper titles

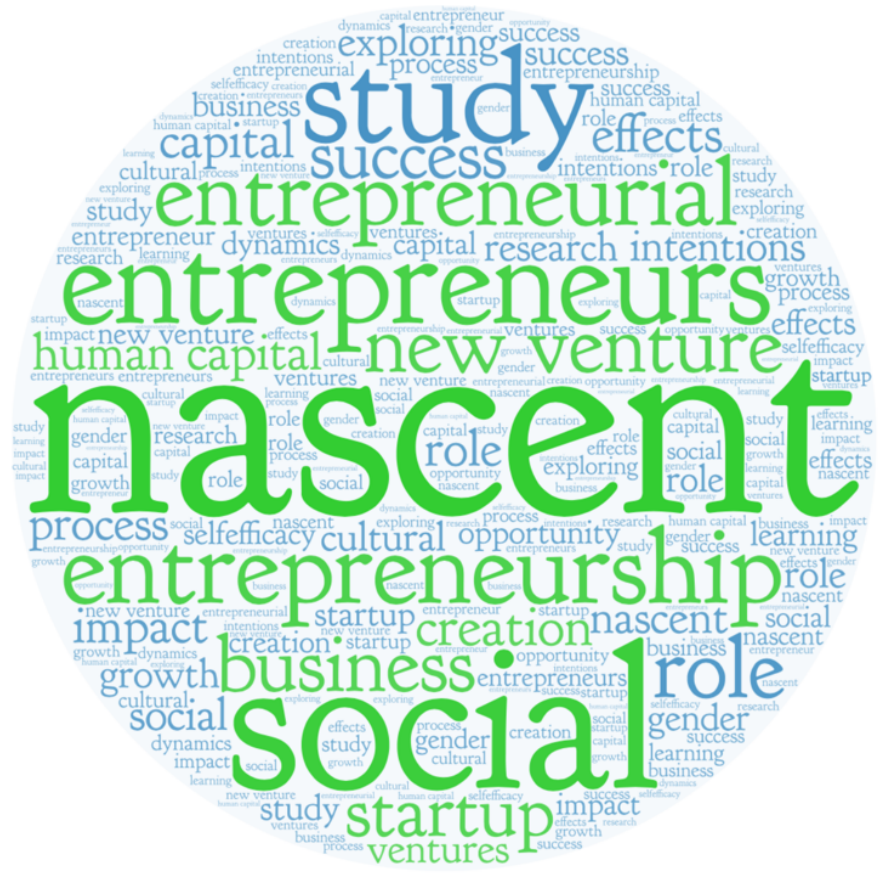

Source: own illustration by WORDij and WordArt sofwares

Figure 5: Most frequently 30 words in paper keywords

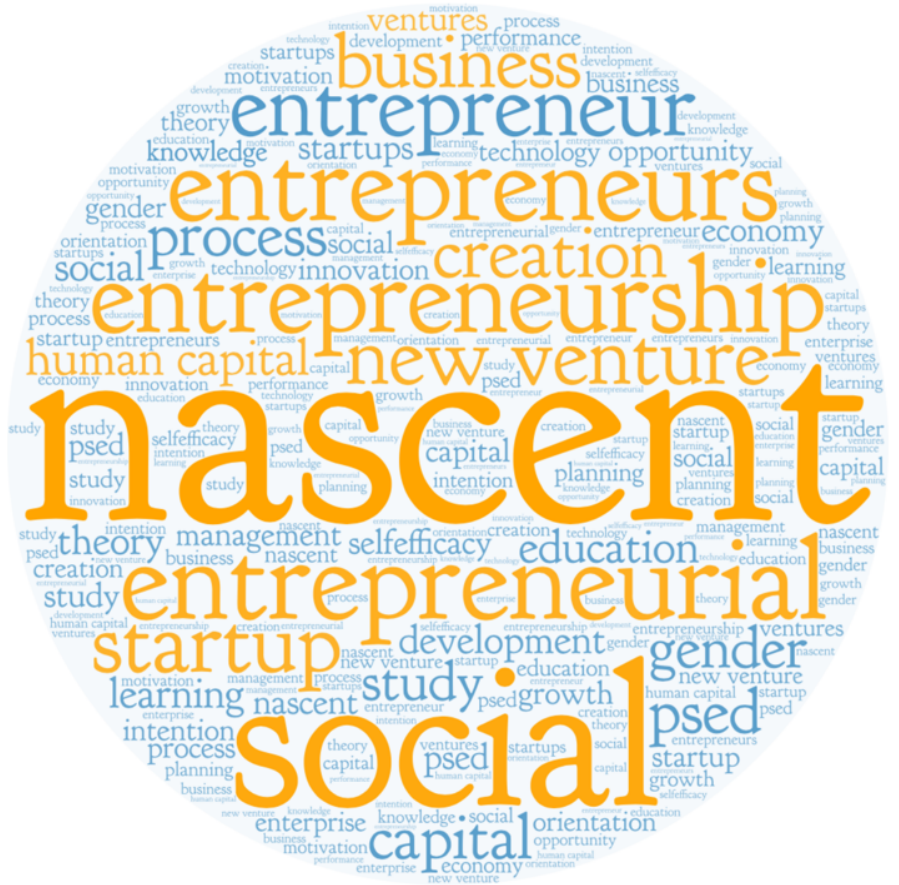

Source: Own illustration by WORDij and WordArt sofwares 
Through the search performed I found new relevant keywords that could help my future research about the nascent entrepreneurship. In the list below, I have collected the 10 most common hits (both in titles and keywords):
a) nascent
b) entrepreneurship
c) entrepreneurial
d) entrepreneurs
e) social
f) startup
g) business
h) venture
i) creation
j) human

Based search keywords can identify (as nascent, entrepreneurship and the synonyms of it), however other connecting words can see in the word clouds and also in the short list. Terms and their synonyms are included in the list above (and in the whole list of results), such as social, capital, human, startup, process, management, performance etc.

This exploratory study also shows the following topics can be segmented during the keywords: geographic, focus, perspective, factor, goal, research.

In a previous study (Aranyossy \& Szabó, 2020) different themes (variables) were identified such as human capital, business planning, social capital, environment, entrepreneurial intention. The results indicate a close similarity to each other.

Using the words above, new literature research can be done by combining the keywords to have a more in depth-knowledge about the topic and segment them to different keyword categories. 


\section{Conclusion and directions for future research}

In this study I have sought to better understand the current state of research focusing on 'nascent entrepreneurship'. In order to take the first step for the exploratory research, I conducted a systematic literature review and then bibliometric- and quantitative analysis of content based on bibliographic data, titles and keywords in academic articles.

The results show that, the topic attracted increasing scientific interest in the last decades, more and more studies are being carried out on nascent entrepreneurship. The most articles had been published in high quality ranked journals (in particular entrepreneurship journals), which show the professionality and limitations of the topic. Working from such articles, it is a great possibility for future research and write publication in high-ranking journals.

In my opinion, it is a great research topic to explore new possibilities in this field, as more and more studies are being prepared. Based on the results, I became sure of the topic's relevance, which can be continued by identify different keyword categories in subsequent research. It is important to note that, this study is also related to previous results, which proves the direction of the research.

Additional option to perform a text analysis also in the abstracts and make word pair analysis. Accordingly, the topic will be thoroughly limited, I am able to find the most relevant articles and do specific research in the future (for example, a qualitative content analysis from the selected articles).

\section{References}

Aranyossy, M. \& Szabó, K. (2020). What affects entrepreneurial intention? A systematic literature review on nascent entrepreneurship and motivational background. In: N. Deutsch, (Eds.) Diversity of Business Development Vol. V.: Thought-provoking ideas and notes

(pp. 25-38). Saarbrücken, Germany: Lambert Academic Publishing

Biggadike, E.R. (1979). Corporate diversification: Entry, strategy, and performance. Cambridge:

Division of Research, Graduate School of Business Administration, Harvard University.

Brush, C.G. (1995). International entrepreneurship: The effects of firm age on motives of internationalization. New York: Garland Publishing Co.

Dimov, D. (2007). From opportunity insight to opportunity intention: The importance of person-situation learning match. Entrepreneurship Theory and Practice, 31(4), 561-583. https://doi.org/10.1111/j.1540-6520.2007.00188.x 
Gelderen, M.V., Thurik, R., \& Bosma, N. (2006). Success and risk factors in the pre-startup phase. Small Business Economics, 26(4), 319-335. https://doi.org/10.1007/s11187-004$6837-5$

Harper, D.A. (2008). Towards a theory of entrepreneurial teams. Journal of Business Venturing, 23(6), 613-626. https://doi.org/10.1016/j.jbusvent.2008.01.002

Hopp, C. \& Sonderegger, R. (2015). Understanding the Dynamics of Nascent EntrepreneurshipPrestart-Up Experience, Intentions, and Entrepreneurial Success. Journals Small Business Management, 53(4), 1076-1096. https://doi.org/10.1111/jsbm.12107

Jáki, E., Molnár, E.M. \& Kádár, B. (2019). Characteristics and challenges of the Hungarian startup ecosystem. Vezetéstudomány/Budapest Management Review, 50(5), 2-12. https://doi.org/10.14267/VEZTUD.2019.05.01

Kunkel, S.W. (1991). The impact of strategy and industry structure on new venture performance. University of Georgia: Unpublished Doctoral Dissertation

Robinson, K.C. (1999). An examination of the influence of industry structure on eight alternative measures of new venture performance for high potential independent new ventures. Journal of Business Venturing, 14(2), 165-187.

https://doi.org/10.1016/S0883-9026(97)00083-9

Scopus website 2020. 'Number of published articles with the keyword »nascent entrepr* «" www.scopus.com

Schaper, M. \& Volery, T. (2004). Entrepreneurship and Small Business: A Pacific Rim Perspective. Milton, Qld.: John Wiley \& Sons Australia.

Shrader, R.C., Oviatt, B.M. \& McDougall, P.P. (2000). How New Ventures Exploit Trade-Offs among International Risk Factors: Lessons for the Accelerated Internationalization of the 21st Century. Academy Management Journal, 43(6), 1227-1247. https://doi.org/10.2307/1556347

Teece, D.J. (2007). Explicating dynamic capabilities: The nature and microfoundations of (sustainable) enterprise performance. Strategic Management Journal, 28(13), 1319-1350. https://doi.org/10.1002/smj.640

van Stel, A., Storey, D.J. \& Thurik, A.R. (2007). The Effect of Business Regulations on Nascent and Young Business Entrepreneurship. Small Business Economics, 28(2-3), 171-186. https://doi.org/10.1007/s11187-006-9014-1 